\title{
Para una crítica inmanente del liberalismo. Theodor Adorno y la cuestión del individuo en Mínima Moralia.
}

\author{
Gisela Catanzaro ${ }^{1}$
}

DOI 10.20399/P1982-999X.2016v1n3pp62-80

\begin{abstract}
Resumen: A diferencia de lo que sucede con otros pensadores asociados al marxismo occidental -de G. Lukacs a L. Althusser, pasando por distintos miembros de la Escuela de Frankfurt-, las reflexiones ético-políticas de Th. Adorno suelen remitirnos a la tradición liberal del pensamiento, en particular en lo que respecta a su categoría central: la de individuo. En efecto, tan persistente como la problematización de la autonomía, la crítica ideológica de la personalidad autoritaria o el trazado de la genealogía violenta del sí mismo, parecería ser en su obra la negativa a realizarlas yendo "más allá" del individuo o apelando a alguna otra lógica que lo complemente. Sin embargo, lejos de la realidad aproblemática e inmediatamente reconocible por todo el mundo, el "individuo" adorniano es -como en Althusser, aunque por otros motivosuna suerte de enigma que exige desciframiento y que, si nos reenvía al liberalismo, lo hace en todo caso a uno "fuera de quicio", acosado por sus propios fantasmas. Aportar algunas claves interpretativas para leer esa figura cifrada es la tarea que nos proponemos abordar aquí partiendo de una relectura de Minima Moralia.
\end{abstract}

Palabras clave: Th. Adorno - Individuo - Liberalismo - Minima Moralia

Abstract:In contrast to other Occidental Marxists -from G. Lukacs to L. Althusser going through different members of the Frankfurt School-, Adorno's ethic-political reflections usually send us back to the liberal tradition of political thought, starting with its main cathegory: the individual. As persistent as his problematization of authonomy, his ideological critique of authoritarian personality or his drawing of the violent geneology of the self, is his negative to perform them going beyond the individual or appealling to any other logic in order to "complement" it. However, far from that aproblematic reality that anyone can immediately recognize, Adorno's "individual" is a kind of enigma that requires to be deciphered and which send us back to a "liberalism" but "out of joint", "haunted" by its own ghosts. To contribute with some interpretative clues in order to read that weird figure is the task we asume here departing from Minima Moralia

Keywords: Th. Adorno - Individual - Liberalism - Minima Moralia

\section{Introducción}

$\mathrm{Si}$, urgidos por los desafíos emergentes de nuestra actual coyuntura, volvemos a interrogar la obra de Theodor Adorno respecto de aquello que, no sólo en el totalitarismo sino también en la democracia, amenaza a esta última, nos veremos inmediatamente confrontados con una serie de preocupaciones prioritariamente

\footnotetext{
${ }^{1}$ Doctora en Ciencias Sociales por la Universidad de Buenos Aires, Argentina, Investigadora adjunta del Consejo Nacional de Investigaciones Científicas y Técnicas (CONICET) en el Instituto de Investigaciones Gino Germani y profesora en las carreras de Ciencia Política y Sociología de la Facultad de Ciencias Sociales UBA.
} 
asociadas a -y conjugadas en los lenguajes de- la tradición liberal del pensamiento político. Desde sus reflexiones sobre la "personalidad autoritaria" a Mínima Moralia, pero también desde Actualidad de la filosofía a Consignas, la "primacía del universal", el colectivo homogeneizante, y una totalidad tan opresiva como ideológica, retornan una y otra vez como los peligros concretos frente a los cuales un pensamiento atento a lo falso de la presunción de reconciliación, se ve obligado a intentar rescatar lo que se halla en inminencia de desaparición: la autonomía; la consideración de cada uno frente al reconocimiento igualitario de todos; el individuo.

Es indudable que esas reflexiones "ético-políticas" 2 elaboradas por Adorno exceden el marco liberal de su formulación ya sea allí donde enlazan la denunciada intolerancia frente a la singularidad con la lógica equivalencial desplegada por el capital, como donde esa crítica ético-política del todo se conjuga inextricablemente con una crítica dialéctica del conocimiento dominante en la que son expuestos los límites idealistas-empiristas de aquél pensamiento liberal. Sin embargo, no menos notoria resulta la asimetría existente entre las dimensiones ético-política -por una parte- y teórico-metodológica -por otra parte- de la crítica adorniana de la totalidad. Porque mientras la disputa con el "positivismo" se da como despliegue de la dialéctica interna de aquél, pero, precisamente, desde la no inmanencia -esto es: desde una aproximación "dialéctica"-, la reflexión ético-política de Adorno parecería, en cambio, no abandonar en ningún momento el "campo de la problemática" dispuesto por el liberalismo.

Esto último resulta particularmente notorio en el caso de Mínima Moralia, donde más que de una reflexión ético-política, parecería necesario hablar de una reflexión moral dada a expensas de lo político en un gesto máximamente próximo a esa tradición liberal que según Carl Schmitt "elude o ignora al Estado y a la política de un modo genuinamente sistemático, y en su lugar se mueve en el seno de una polaridad típica y recurrente entre dos esferas heterogéneas, las de ética y economía”: Una tradición prosigue Schmitt- cuya "desconfianza crítica hacia el Estado y la política se explica fácilmente por los principios de un sistema para el cual el individuo es y debe seguir siendo tanto terminus a quo como terminus ad quem". ${ }^{3}$

Mínima Moralia, texto que al igual que otros escritos por Adorno se resiste a tomar cualquier disociación de "principios" (políticos, morales, económicos...) como

\footnotetext{
${ }^{2}$ Más abajo discutimos la posibilidad de sostener esta categoría respecto a Mínima Moralia.

${ }^{3}$ SCHMITT, C.. El concepto de lo político. Madrid: Alianza, 1998, p. 98-99.
} 
principio, acusa sin embargo una disociación real de ética y política en una época donde según él se "extrema la antítesis de vida pública y existencia individual" drástico desacople de escalas hace que la dimensión en que transcurre lo político sólo pueda ser registrada automáticamente pero no ya experimentada en términos morales por el individuo 5 . Aunque no "por principio" el ámbito de reflexión de este texto se encontraría, en efecto, y en consonancia con el liberalismo denunciado por Schmitt, acotado a esa dimensión privada de la vida en la cual el individuo emerge como figura central, y donde la política queda perfilada, en el mejor de los casos, exclusivamente de un modo negativo en las alusiones a una oscura e impermeable "Razón de Estado".

Así, podría sostenerse que un pensamiento de lo político tendría que prescindir de Adorno. O bien que, aún cuando no se tratara sencillamente de sancionar su caducidad o la necesidad de su abandono, una reapropiación de los planteos de Adorno a la luz de la cuestión de la democracia en nuestra actualidad precisaría ser conciente de la limitación liberal de su pensamiento para eventualmente buscar complementar sus reflexiones con otros aportes que permitieran pensar aquello que él no puede pensar, así como formular la necesaria crítica ideológica del liberalismo y de todas las categorías que conforman su andamiaje conceptual: empezando por la evidencia del individuo y el presupuesto de la armonía social invisiblemente garantizada. Sin embargo, la intuición orientadora de las páginas que siguen sugiere que es precisamente en la elaboración compleja y sutil de tales críticas donde el planteo de Adorno revela su mayor actualidad. Y esto no sólo debido a los contenidos que provee, sino a la misma modalidad de su reflexión que, en tanto crítica situada e inmanente, podría ayudarnos a determinar algunas limitaciones de ciertas tendencias actuales de la filosofía política.

\section{1.- Pensamientos finitos e inacabados}

"Quien quiera conocer la verdad sobre la vida inmediata tendrá que estudiar su forma alienada"

\footnotetext{
${ }^{4}$ ADORNO, Th.. Minima Moralia. Madrid: Editora Nacional, 2002, p. 171.

5 "Quien comete acciones que, según las normas reconocidas, son contrarias a la rectitud, como la venganza contra los enemigos o la falta de compasión, apenas es conciente de la culpa, y sólo mediante un penoso esfuerzo puede imaginársela [...] Sin embargo, cuando se piensa en faltas personales de tacto, microorganismos de injusticia que probablemente nadie notó [...] pueden llenar al delincuente de continuo arrepentimiento e insoportable mala conciencia, y en ocasiones de tan sofocante vergüenza que sería incapaz de confesárselo a nadie, ni aún a sí mismo". ADORNO, Th.. Minima Moralia. Op. cit., p. 171.
} 


\begin{abstract}
"A la vista de la conformidad totalitaria que proclama directamente la eliminación de la diferencia como razón es posible que hasta una parte de la fuerza social liberadora se haya contraído temporalmente a la esfera de lo individual" Adorno, Th. Minima Moralia ${ }^{7}$
\end{abstract}

Entre las características habituales de las formas lingüísticas implicadas en los clichés socialmente aceptados se destaca su atemporalidad. Sin constituir una condición necesaria ni suficiente de su contextura ideológica, las autoevidencias en que se traman nuestros sentidos comunes parecerían, las más de las veces, querer valer para todos los tiempos y conseguirlo gracias al borramiento de lo que Walter Benjamin llamaba "el índice histórico de la imágenes" ${ }^{\prime}$, o bien -como se diría en una prosa más próxima al análisis estructural- gracias a la supresión en el enunciado de las marcas de la situación de enunciación.

Leídos sobre este trasfondo -que, como veremos en seguida, dista de ser caprichoso- en los fragmentos de Minima Moralia que escogimos como epígrafes y puntos de partida de nuestra reflexión, resalta ante todo el anclaje histórico de lo dicho y pensado. Un anclaje que si para Adorno no "justifica" al pensamiento al mostrarlo como parte de una totalidad significativa pretérita que garantizaría de antemano su sentido y su valor, sí "ancla" negativamente lo dicho al dejar expuestas las marcas de su finitud, y tornar legible -por contrapartida- la violencia implicada en la pretensión de eternidad de los enunciados que se quieren "sin tiempo ni lugar".

Muchos de esos enunciados provienen de la Filosofía. A ellos responde Adorno poniendo de relieve el carácter "referido" de la reflexión, que se produce "a la vista" de algo que le ha salido al paso, como respuesta a una estructuración actual del mito, y no como un pensamiento desplegado en sus propios términos válidos para todo tiempo y lugar. Como crítica de una tal violencia eternizante podrían concebirse, de hecho, los

\footnotetext{
${ }^{6}$ ADORNO, Th.. Minima Moralia. Op. cit., p. 7.

${ }^{7}$ Ibidem, p. 10.

${ }^{8}$ BENJAMIN, W.. "La obra de los Pasajes - Convoluto N" en La dialéctica en suspenso. Santiago de Chile: ARCIS-LOM, 1996, p. 122.
} 
persistentes cuestionamientos realizados por Adorno al idealismo ya sea en sus formulaciones científico-logicistas o en las (neo)ontológicas, y que alcanzan también a las corrientes formalistas de la Sociología. En todos los casos se trata para él de modos de pensamiento que de diversas formas "afectan eternidad" en tanto rechazan su propio ser suscitados, y a los cuales opone la dialéctica en tanto problematización del origen que relee como mediado aquello que en cada caso se querría dato último.

Atendiendo a estas consideraciones "epistemológicas", lo primero que cabría señalar a propósito de la aproximación adorniana al individuo, es su carácter no "original" sino urgido. Y esto en un doble sentido: si por un lado la consideración del "individuo" se le impone al intérprete materialista -antes que escogerla él entre un acervo de tópicos siempre disponibles para el ejercicio de una Filosofía eterna- y en ese sentido lo urge, además lo hace cuando él mismo está urgido, esto es, en el momento de su decadencia, cuando tanto la centralidad de la categoría de individuo como su misma existencia han perdido evidencia.

Enseguida volveremos sobre ello a propósito de Mínima Moralia. Y no obstante cabría anticipar que, en toda la obra de Adorno, es una cierta urgencia en que se halla la experiencia individual la que a su vez urge un pensamiento que sólo se da como pensamiento emplazado. "Emplazado", sin embargo, y esto es lo fundamental, menos en una "corriente del pensamiento", que en una situación en la cual quedan expuestas también- las insuficiencias de la "corriente de pensamiento" que hace de esa figura del individuo su motivo central. Dicho de otro modo, en la "emplazada" reflexión adorniana sobre el individuo quedan expuestas las insuficiencias en el trato dado al individuo por parte del liberalismo, lo cual produce la situación paradójica de no poder ser liberal precisamente por fidelidad a aquello que el liberalismo tiene de verdadero pero que sistemáticamente traiciona al plantearlo como principio y como algo con lo que es posible contar.

\section{2.- Desbordes del liberalismo}

En la persecución de intereses absolutamente particulares por parte de cada individuo puede estudiarse con la mayor precisión 
la esencia de lo colectivo en la sociedad falsa.

Adorno, Th. Minima Moralia9

La figura actual de lo colectivo en sí misma carece de lenguaje. Hoy ningún colectivo al que confiar la expresión del sujeto es ya sujeto. Adorno, Th. Minima Moralia ${ }^{10}$

Desde el mismo comienzo de Mínima Moralia el individuo aparece a la vez como un lugar de llegada y como algo no con-temporáneo o anacrónico, algo que no es del todo "presente" en el sentido de que no coincide con los tiempos. Es un lugar de llegada, en primer término, para la reflexión crítica que encuentra en la experiencia individual la única instancia en que aún es posible leer la persistencia del antagonismo al que más arriba aludimos como antítesis de vida pública y existencia individual- en el presente. Paradójicamente, no obstante, esa instancia individual "resistente" muestra como particularmente reveladora en tanto anacrónica, es decir, donde y cuando el individuo ya ha sido sobrepasado y perdido algo de su con-temporaneidad.

"Cuando el individuo, como todos los procedimientos individualistas de producción, aparece históricamente anticuado y a la zaga de la técnica, le llega de nuevo, en cuanto sentenciado, el momento de decir la verdad frente al vencedor"12, escribe Adorno. Y esta relación condicional que la categoría de individuo mantiene con la verdad es un primer índice de su "distancia" con la tradición liberal. Mientras para esta última el individuo constituye una categoría primera, válida para todos los tiempos y que remite a una evidencia actual, para Adorno es la experiencia que el individuo tiene de sí mismo en la edad de su decadencia - la experiencia de su nulidad- la que contribuye "a un conocimiento que él simplemente encubría durante el tiempo en que, como categoría dominante, se afirmaba sin fisuras."13

Así, el individuo resulta un punto de llegada en este primer sentido porque, a la inversa, en su postulación como originario, como terminus a quo -digamos para retomar

\footnotetext{
${ }^{9}$ ADORNO, Th. Minima Moralia. Op. cit., p. 38.

${ }^{10}$ Ibidem, p. 212.

${ }^{11}$ Más adelante retomaremos la cuestión del carácter individual de la resistencia.

${ }^{12}$ ADORNO, Th. Minima Moralia. Op. cit., p. 122.

${ }^{13}$ Ibidem, p. 10.
} 
el planteo de Schmitt-, no sólo vuelve a afirmarse para Adorno el culto de la inmediatez que consagra lo primero sólo gracias al rechazo de su propio ser mediado, sino también porque al dar por descontada la existencia y centralidad de la instancia individual en la configuración actual del mundo, el pensamiento que parte de él resulta necesariamente ciego a su padecimiento e impotencia, así como a ese estado actual del mundo que los produce. Dicho de otro modo, la afirmación del individuo como primero y dado es ideológica. Lo es porque desconoce (en general) la mediación social de lo individual; pero lo es sobre todo porque, tras la afirmación de la centralidad eterna del individuo y la celebración de su esplendor, queda velada -en particular- la producción social de su nulidad en la sociedad de masas, y, junto con ella, queda velado el carácter falsamente reconciliado de la totalidad, lo falso de la "armonía" presupuesta en el pensamiento liberal.

Aquí quedan planteados los términos de una de las críticas centrales de Adorno al liberalismo político y sobre la que volveremos más adelante: por sus mismos puntos de partida, éste resulta incapaz de realizar aquello que afirma, esto es, su voluntad de hacer justicia a la instancia individual. Pero precisamente esa alusión a una reconciliación inactual nos remite -antes- al segundo sentido en que el individuo sería, para Adorno, un punto de llegada; esto es: en tanto afirmación de la singularidad irreductible frente a la lógica actualmente dominante de la equivalencia y la sustituibilidad generalizadas. El término clave en la configuración de este segundo problema es "homogeneización". El individuo es inactual, en esta nueva dimensión, menos por encontrarse ya en decadencia que por no haber devenido aún. Es "inactual", en otros términos, en tanto la "libre comunicación de lo diferente" -como la llama a veces Adorno- supondría una ruptura de la igualación homogeneizante a la que lo singular está actualmente sometido bajo el imperio de la sociedad equivalencial.

Es de esa lógica homogeneizante que emerge, como uno de sus productos, el individuo aislado que concurre al mercado guiado por su propio interés egoísta y que, a los fines del intercambio, resulta esencialmente sustituible por cualquier otro ejemplar de la especie. Pero "el pensamiento dialéctico -escribe Adorno- se opone a toda cosificación también en el sentido de negarse a confirmar a cada individuo en su 
aislamiento y separación" ${ }^{14}$. Lo que hace, en cambio, es definir su aislamiento como producto de lo general:

Precisamente en su individuación refleja el individuo la ley social inexplícita de la sin embargo bien conducida explotación [...] $\mathrm{Si}$ hoy parece persistir un vestigio de lo humano únicamente en el individuo en tanto que perece, ese vestigio exhorta a poner fin a esa fatalidad que individúa a los hombres únicamente para poder separarlos tanto más perfectamente en su aislamiento. ${ }^{15}$

Lejos de constituir la última palabra sobre el individuo, el aislamiento es para Adorno la cicatriz dejada por aquello que, en la sociedad, posterga indefinidamente la posibilidad real de una individuación no cosificada, y que constriñe en cambio al individuo a la identidad sin mixtura y "auténtica” de lo siempre igual. Veamos esto más de cerca.

En la crítica adorniana "aislamiento" y "homogeneización" no forman parte de sistemas heterogéneos y exteriormente enfrentados entre sí, sino que aparecen como elementos inherentes a la dinámica de la equivalencia. Allí donde triunfa, es decir, donde llega a todas partes y consigue configurar el mundo a su medida, ésta produce el aislamiento del individuo típico de las sociedades industriales avanzadas; las mismas sociedades que, a su vez, proveen la contrafigura de la masa como la instancia en la que esos átomos aislados se funden. Esa fusión, sin embargo, no puede conceptualizarse sin más como algo que le sobrevenga a las mónadas desde afuera, sino que ya estaba implicada en la misma sustituibilidad de los ejemplares operante en la constitución de los átomos aislados. Por ello, no menos que la masa, el individuo aislado constituye en Mínima Moralia un auténtico exponente del triunfo de la equivalencia y su lógica homogeneizante. Así como aislamiento y homogeneización son interpretados por Adorno menos como alternativas que como elementos constitutivos de una misma dialéctica, el individuo aislado y la masa son concebidos como síntomas de la misma deformación social de lo singular y de lo colectivo en ese presente histórico.

De esto último no se deriva, sin embargo, la necesidad de postular la simple identidad de las figuras del individuo aislado y la masa. Ello implicaría pasar por alto su desigual dominancia en coyunturas históricas determinadas así como el nítido acento

${ }^{14}$ ADORNO, Th. Minima Moralia. Op. cit., p. 63.

${ }^{15}$ Ibidem, p. 141-142. Volveremos sobre este fragmento en el tercer apartado. 
colocado por Adorno sobre la crítica de la totalidad en una coyuntura marcada por los totalitarismos, el monopolio, la razón de Estado, los medios masivos de comunicación, etc.. Pero la crítica adorniana de la interpretación liberal que entiende el aislamiento y la homogeneización, el individuo atomístico y la masa, como elementos simplemente externos y alternativos, crítica que se despliega mostrando -en cambio- la profunda solidaridad existente entre ellos en una sociedad determinada y de la cual son producto, esa crítica no podría satisfacerse con la mera postulación de una inversión por la cual el término dominado pasara a la posición dominante. No se trata de promover el fortalecimiento ${ }^{16}$ del individuo aislado contra la masa. Antes bien, de lo que se trataría para una perspectiva de la reconciliación pendiente, sería de un individuo y un colectivo transmutados, diversos de lo que han llegado a ser en cada caso.

Podemos ahora ahondar algo más en el segundo sentido en que Minima Moralia nos presenta al individuo como punto de llegada. Si más arriba sostuvimos que la lectura crítica descubre en la experiencia individual un potencial expresivo de la violencia acaecida en tanto conserva parcialmente las marcas del antagonismo, el individuo es asimismo un lugar de llegada en tanto no-contemporáneo también en el sentido de lo que no ha llegado a ser. El individuo como lugar de llegada es, aquí, diverso al individuo que es (el individuo aislado y confinado en su aislamiento). La marca de su inactualidad lo distingue, como sucedía en el primer caso, de esa individualidad que, en tanto categoría dominante "se afirmaba sin fisuras", como figura rutilante del presente. Pero mientras la individualidad decadente revelaba como ideológica ante todo la confianza liberal en la vivacidad, pujanza y espontaneidad de lo ya mutilado, vuelto impotente y dirigido, en este segundo caso se llama ideología a la pretensión de que ha sido consumado lo que aún permanece pendiente. Una individuación pendiente que no puede decirse sencillamente en los términos de una liberación (negativa) de lo singular respecto del colectivo, esto es, a expensas de lo social trans-individual, sino que alude antes bien a otro tipo de relación social basada en aquello a lo que Adorno se refiere en el siguiente pasaje con el término "mímesis":

La autenticidad no es otra cosa que el obstinado y altanero encastillarse en la forma monadológica que la opresión

\footnotetext{
${ }^{16} \mathrm{Al}$ proyecto de un tal fortalecimiento Adorno respondería del mismo modo que frente a la apología neo-romántica de la corporalidad y la naturaleza que desconoce su devenir corpus, cadáver, en el decurso del proceso histórico civilizatorio tal como este se ha consumado. Al respecto, se pueden consultar los fragmentos filosóficos del final de Dialéctica de la Ilustración, en particular, "Interés por el cuerpo" y "Hombre y animal".
} 
social imprime al hombre. Lo que no quiere marchitarse prefiere llevar el estigma de lo inauténtico. Entonces vive de la herencia mimética. Lo humano se aferra a la imitación: un hombre se hace verdaderamente hombre sólo cuando imita a otros hombres. En este comportamiento, forma primaria del amor, olfatean los sacerdotes de la autenticidad la pista de aquella utopía que podría sacudir la estructura del dominio. ${ }^{17}$

El individuo como lugar de llegada es indiferente a la (falsa) alternativa entre encasillamiento (en el sí mismo) y fusión (en la masa), una dualidad modelada en el patrón de la mismidad pura y sin mixtura cuyo cuestionamiento Adorno emprende aquí y en otros textos bajo el título de una crítica de la “autenticidad". La lógica impulsada por esta última garantiza la reproducción de la estructura de dominio en tanto genera las identidades en las que aquél se sostiene, es decir, en tanto reprime las múltiples afinidades entre lo existente puestas de relieve en el impulso mimético, en favor de la producción de interioridades homogéneas y sin ventanas cuya única forma de afirmarse en la existencia depende de la posibilidad de sostener la independencia del sí mismo respecto de lo otro, y de la eliminabilidad de la presencia de lo otro en el sí mismo.

La jerga de la autenticidad, así como la dicotomía amigo-enemigo a partir de la cual Carl Schmitt piensa la especificidad de lo político, no sólo no dicen la última palabra sobre "la" política ${ }^{18}$, sino que constituyen para Adorno expresiones de un "empobrecimiento de las relaciones entre las personas [...que tiende] ya antes de toda formación política de la voluntad y toda fijación de rótulos, al facismo." Su modelo es el de la administración y la mirada evaluadora del manager al que las personas con las que entra en contacto se le convierten de antemano en obstaculizadores o facilitadores, y finalmente en admisibles o eliminables ${ }^{19}$. Pero el sentido de esta relación social empobrecida, señala Adorno,

\footnotetext{
${ }^{17}$ ADORNO, Th. Minima Moralia. Op. cit., p. 146.

18 Entre otras cosas porque no hay "la" política sino configuraciones históricas de la politicidad, planteadas en determinadas y singulares relaciones con lo que no es política: la moral, la economía, el conocimiento, el arte, lo ideológico.

19 “Quien hace del juicio sobre las aptitudes un asunto personal, ve a los enjuiciados, por una especie de necesidad tecnológica, como de los suyos o de los otros, como individuos de su especie o de otra, como
} 
ya se anunciaba en el "término catolicismo, una palabra griega para la latina totalidad -que los nacionalsocialistas han hecho realidad- [...y que] significa hacer equivaler lo diferente a lo adverso." Si "lo auténtico" es -en la obra de Adorno- la forma vigente en que se constituyen de modo dominante las identidades individuales y colectivas, "mímesis" 20 nombra tanto un individuo como un colectivo trasmutados.

\section{3.- Armonía y totalitarismo liberal}

La doble perspectiva sobre la individualidad que hemos visto desplegarse en Mínima Moralia, esa aproximación bifocal que la trata como punto de llegada (y no de partida) deteniéndose en los aspectos contradictorios de su in-actualidad, le permite a Adorno extrañar la categoría liberal del individuo sin confrontarla en ningún momento desde el exterior. En algún sentido -que no obstante enseguida intentaremos desabsolutizar- podríamos decir que en este texto el individuo se vuelve espectral: entre lo "ya inactual" de una autonomía con la que dista de ser evidente que podamos contar, y lo "todavía inactual" de una individualidad no estandarizada, la confianza liberal en el individuo que es, se muestra en su complicidad -a pesar de las apariencias y declaraciones- con las fuerzas sociales que perpetúan indefinidamente el sometimiento de lo particular. Paralelamente, el individuo sólo parecería verdadero en tanto espectro, espectralizado, no siendo enteramente algo que actualmente es ¿Sería lo mismo dictaminar sencillamente la falsedad tout court de la categoría de individuo? ¿Sostener que, en tanto presencia, el individuo es falso, además de pieza clave de un discurso ideológico, y que más convendría pasar a otra cosa? Esta pregunta nos sugiere dos respuestas negativas de muy diversa índole y que resumiríamos (mal) del siguiente modo: a) no, porque ello haría imposible la crítica, y b) no, porque la crítica no es todo. Antes de terminar, consideremos brevemente estas dos negativas a "ir más allá" del individuo.

sus cómplices o sus víctimas". Esta y todas las citas del presente párrafo pertenecen al fragmento 85 de Minima Moralia. Op. cit., p. 123-124.

${ }^{20} \mathrm{O}$ "amor" que por momentos parecen sinónimos: "El amor es la capacidad de percibir lo semejante en lo desemejante.” Minima Moralia. Op. cit., p. 182. 
La simple eliminación de la categoría de individuo -o una renominación menos mítica de lo mentado por él- impediría, en primer lugar, formular la crítica de lo que funciona como ideología en un presente determinado, y aún cuando un nuevo nombre fuera capaz de llamar mejor a aquello a lo que el individuo alude, las fuerzas sociales que con el bautismo quedarían por fuera de la nominación, no por ello dejarían de ser efectivas $^{21}$. Lo que oprime al individuo -también allí donde confía en su existencia, es decir, en el liberalismo- precisa ser nombrado, conceptualizado; y es precisamente esa conceptualización la que no se da a expensas de la categoría de individuo (más allá de ella, sustituyéndola) sino con la elaboración de su crítica. Pero además en Mínima Moralia esa crítica tiene la potencia de descubrir oscuras afinidades entre el liberalismo y lo que se presenta en primera instancia como su "absolutamente otro": la pretensión "totalitaria" de una totalidad autosuficiente y armónica, dotada de una lógica transindividual propia y superior a la de los individuos.

Adorno descubre esta afinidad secreta en su crítica a una figura que no cesa de invocar: la dialéctica hegeliana. Si, como mencionábamos más arriba, rechaza la hipostatización de la "categoría básica de la sociedad burguesa, el individuo"22 y reclama un conocimiento de la sociedad de la que es producto, lo mediador -la sociedad- tampoco puede ser afirmado según él como un primero al modo en que finalmente sucede en la totalización propuesta por Hegel. Del mismo modo en que sostuvimos que la "elitista" mónada aislada dista de ser la última palabra de Adorno sobre la individuación, es preciso enfatizar los límites que la totalización encuentra en su argumento y que -amén de la alusión crítica al cristianismo referida en el punto anterior- se resumen en el siguiente fragmento:

También donde la no ingenuidad se concibe en el sentido teóricamente responsable de lo que mira más allá, de lo que no se detiene en el fenómeno aislado, de lo que piensa la totalidad, hay una zona oscura. Es simplemente aquel seguir sin poder detenerse, aquel tácito reconocimiento del primado de lo general frente a lo particular en que consiste no solamente el engaño del idealismo que hipostatiza los conceptos, sino también su inhumanidad, que, apenas captado, rebaja lo particular a

\footnotetext{
${ }^{21}$ A propósito de esto siguen siendo esclarecedoras algunas de las más vibrantes páginas de Radiografía de la pampa. La "barbarie" de Sarmiento nombraba mal el peligro, dice allí Ezequiel Martínez Estrada, pero cuando todo fue "civilización" el mal ya no pudo ser nombrado y zonas enteras de la realidad cayeron en la irrealidad.
}

${ }^{22}$ ADORNO, Th. Minima Moralia. Op. cit., p. 9. 
estación de tránsito para finalmente resignarse con demasiada rapidez, no sin dolor y sin muerte, en aras de una conciliación que meramente existe en la reflexión -es, en última instancia, la frialdad burguesa, que con excesiva complacencia suscribe lo inevitable. El conocimiento sólo puede extenderse hasta donde de tal modo se aferra al individuo que, por efecto de la insistencia su aislamiento se quiebra. ${ }^{23}$

En la primacía de lo general donde concluye el gesto totalizador del idealismo, se revela para Adorno su perfil apologético de la sociedad opresiva: la postulación de una "conciliación que meramente existe en la reflexión" y de cuya no-verdad sólo la experiencia individual podría dar testimonio. Por eso "casi podría decirse que [...] la verdad depende del tempo, de la perseverancia y duración del permanecer en el individuo" 24 , es decir, de la permanencia de la reflexión no en la categoría rutilante de individuo, sino en esa experiencia individual que guarda las huellas de la sociedad antagonista y a la cual el pensamiento debe aferrarse puesto que es allí donde, a pesar de todo, según Minima Moralia ésta puede ser mejor leída como lo que es.

Pero si en el Hegel apologeta de la totalidad se conjugan, por una parte, un límite epistemológico: el desconocimiento de aquello que la totalidad es (antagonismo) debido a la hipostatización de la reconciliación universal, y un límite ético: la "inhumanidad" de un sistema condenado a "seguir sin poder detenerse" a pesar del dolor y la muerte de lo particular, esto no sucede para Adorno a expensas del pensamiento liberal sino precisamente debido al liberalismo de Hegel:

\footnotetext{
${ }^{23}$ Ibidem, p. 66

${ }^{24}$ Ibidem, p. 69. El tema de la permanencia dialéctica en el individuo resulta sumamente sugerente a la luz de un comentario que realiza Fredric Jameson a propósito de la relación y diferencia entre dialéctica y deconstrucción. Según sostiene el autor en Valencias de la dialéctica, libro donde persigue su "parecido de familia" pero intentando comprender también su conflicto, "ambas trabajan para llevar a la luz las incoherencias estructurales de la 'idea' o de las 'posiciones' o interpretaciones conceptuales que constituyen el objeto de su crítica. Pero allí donde la dialéctica hace una pausa, esperando que la nueva solución 'dialéctica' se congele a su vez y se convierta en una idea o ideología a la que la dialéctica puede volver a 'aplicarse' [...], la deconstrucción se apresura, deshaciendo la incoherencia que había estado denunciando y demostrando que ese resultado analítico aparente es él mismo una nueva incoherecia y una nueva 'contradicción' que a su vez debe ser desarmado." JAMESON, F..Valencias de la diléctica. Buenos Aires: Eterna cadencia, 2013, p. 39. Se trata de una diferencia de tempos, sin duda, pero una que, a su vez, parecería alertar sobre la diferencia entre un modo de la crítica que privilegia la deconstrucción de las interpretaciones ya producidas sobre un objeto, y otro modo de la crítica que vuelve a recomenzar una otra vez su movimiento a partir de las nuevas aristas que el objeto le va revelando a través de las diversas interpretaciones producidas a propósito del mismo pero sin reducirlo a ellas. Tanto en la figura del tratado invocada por Benjamin en el prólogo epistemocrítico de El origen del drama Barroco alemán, como en la consigna adorniana de la "primacía del objeto" parecería retornar una suerte de reclamo excesivo del material en relación a las interpretaciones ya provistas que orienta a la reflexión sobre algo otro y distinto del propio discurso crítico sobre el cual se vuelve, por el contrario, el gesto deconstructivo.
} 
El gesto displicente con que Hegel, en contradicción con su propia teoría, trata continuamente a lo individual proviene, de un modo harto paradójico, de su necesaria adscripción al pensamiento liberal. La representación de una totalidad armónica a través de sus antagonismos le obliga a atribuir a la individuación, por más que la determine siempre como momento impulsor del proceso, sólo un rango inferior en la construcción del todo. ${ }^{25}$

En la sociedad no reconciliada la representación de la armonía es totalitaria antes de hablar en favor de la centralización del poder o aún oponiéndose a ella. Aquí no se trata sólo de que, al presuponerlo como evidencia, el liberalismo resulte intrínsecamente incapaz de atender a la decadencia del individuo y de formular la crítica del mundo (homogeneizante, identitario, equivalencial) que la produce. En la negación del conflicto y la afirmación de la armoniosa composición de los intereses egoístas de cada uno -fundante del liberalismo pero que subyace también a la razón objetiva hegelianael individuo en cierto sentido ha sido siempre-ya abandonado en tanto postulado como esencialmente amoldado a y digerible por la lógica del todo.

Adorno muestra que "liberalismo" y "primacía de lo general" no constituyen alternativas exteriores; muestra que Hegel espectraliza al individuo en el mismo momento en que, junto a la tradición liberal, confía en la racionalidad del Espíritu absoluto, su propia versión de la mano invisible. Y muestra también que el liberal presupuesto de la armonía es totalitario aún antes de que el liberalismo muestre su impotencia -o bien su funcionalidad- frente al totalitarismo. Pero precisamente porque en esa espectralización prematura Adorno lee los rastros de la "frialdad burguesa, que con excesiva complacencia suscribe lo inevitable", él mismo se resiste a la espectralización, insistiendo en la necesidad de no reducir al individuo a un puro no ser. Si en la reflección crítica de Adorno el individuo es inactual decadente o por venir, es también siempre más que un puro espectro. O bien: su no ser, no menos que su ser, conlleva algo de ilusión:

Quien quiera conocer la verdad sobre la vida inmediata tendrá que estudiar su forma alienada, los poderes objetivos que determinan la existencia individual hasta en sus zonas más ocultas. Quien habla con inmediatez de lo inmediato apenas se

\footnotetext{
${ }^{25}$ ADORNO, Th. Minima Moralia. Op. cit., p. 9.
} 
comporta de manera diferente a la de aquellos escritores de novelas que adornan a sus marionetas con imitaciones de las pasiones de otros tiempos cual alhajas baratas y hacen actuar a personajes que no son nada más que piezas de la maquinaria como si aún pudieran obrar como sujetos y como si algo dependiera de sus acciones. La visión de la vida ha devenido en la ideología que crea la ilusión de que ya no hay vida. ${ }^{26}$

La autonomía individual como presupuesto y evidencia de la vivacidad de la vida es ideológica. Pero también la comprobación de que ya no hay vida es ilusión. Y es aquí donde se perfila la segunda razón adorniana para -como si dijéramos- no "abandonar al individuo", para evitar dictaminar sencillamente la falsedad de la categoría de individuo o limitarse a sostener que, en tanto presencia, el individuo es falso. El individuo decíamos en el punto anterior- no puede caer como nombre sin arrastrar también a la ilegibilidad la violencia actual que lo somete, y que lo somete no necesariamente bajo los nombres de la violencia y las invocaciones épicas, sino en la pacífica referencia a las armonías preestablecidas. Pero hay más, porque la crítica no es todo, o mejor: porque el individuo no es sólo el jeroglífico que la crítica descifra sino que es también una débil fuerza de resistencia, poco más que un "vestigio" -como lo llamaba Adorno en uno de los fragmentos citados más arriba- pero un vestigio que "exhorta": "Si hoy parece persistir un vestigio de lo humano únicamente en el individuo en tanto que perece, ese vestigio exhorta a poner fin a esa fatalidad que individúa a los hombres únicamente para poder separarlos tanto más perfectamente en su aislamiento."27

Sin provenir de una presencia plena, rutilante, dominante, la exhortación a poner fin a un tipo determinado de relación social empobrecedora, es tan real y actual como las fuerzas dominantes en función de las cuales se da la estructuración del todo. Adorno se resiste a la tentación de poner las cosas en términos de presencia o ausencia y busca en cambio otra modulación de la presencia/ausencia: la presencia frágil o "débil" -como la llamaba Benjamin-, el vestigio de presencia -como leemos aquí-. Porque no sólo lo que oprime debe ser nombrado, sino que también lo que padece, resiste y "exhorta" exige una nominación, en Mínima Moralia "individuo" no es sólo sido-advenidero sino también nombre de una débil resistencia actual. A lo que -no obstante- inmediatamente hay que agregar: lo que resiste en el individuo no es sólo de naturaleza individual:

${ }^{26}$ Ibidem, p. 7. Enfatizado por mí.

27 Ya citado en nota 14: ADORNO, Th. Minima Moralia. Op. cit., p. 141-142. 
El rechazo de la confusión reinante en la cultura presupone que se participa de ella lo suficiente como para sentirla palpitar, por así decirlo, entre los propios dedos, mas al propio tiempo presupone que de dicha participación se han extraído fuerzas para denunciarla. Tales fuerzas, que se presentan como fuerzas de resistencia individual, no son por ello de índole meramente individual. La conciencia intelectual en la que se concentran tiene un momento social en la misma medida que lo tiene el superyo moral. Dicho momento se decanta en una representación de la sociedad justa y sus ciudadanos. ${ }^{28}$

Si el individuo no es mero espectro, sino también resistencia y exhortación aquí y ahora, hay sin embargo más que individuo en la resistencia "individual". Hay una "fuerza social liberadora" temporalmente "contraída" en una esfera -la de lo individualdonde, estrictamente hablando, para Adorno, no puede ser política pero tampoco moral sino, a lo sumo, contener "microorganismos de justicia". Sólo en la figura de lo colectivo -esa figura que, decía Adorno "actualmente carece de lenguaje" y no puede expresar al sujeto- habría política y moral en un sentido del que aquella actualidad sólo conoce vestigios. Y bueno es reconocerlos como tales, diría Adorno a un liberalismo para el que lo privado curiosamente ha dejado de estar privado -marcado por la limitación- para constituirse en ideal, pero también a un "realismo" que toma por la esencia de lo político lo que no constituye sino un producto particular de ciertas relaciones sociales empobrecidas: la capacidad de configurar de una vez el mundo en la cuadrícula del o bien, o bien.

\section{4.- Para terminar}

Adorno nos arrojaría entonces un liberalismo, pero uno "fuera de quicio", acosado por sus propios fantasmas. A la inversa, no sería desde un más allá del individuo o apelando a alguna otra lógica que lo complemente sino -como si dijéramos"extremando su concepto", como se elaborarían en su obra la genealogía violenta del "sí mismo", la crítica de la "personalidad", o la problematización de la autonomía. Por contrapartida -no obstante- el individuo en cuestión ya no podría identificarse con

\footnotetext{
${ }^{28}$ Ibidem, p. 21.
} 
aquella categoría para nosotros familiar, que promete incesantemente remitirnos a una realidad aproblemática e inmediatamente reconocible por todo el mundo; categoría "simple" de la cual se podría disponer en el proceso de comprensión de realidades "más complejas". El "individuo" en juego en la obra de Adorno sería -antes bien, como en la obra de Althusser aunque por otros motivos- una suerte de enigma que exige desciframiento, y descifrar ese individuo que es más y otra cosa que el individuo "normal”/normalizado pero también más que un fantasma con el fin de complejizar nuestras teorizaciones actuales sobre la democracia, fue la tarea que nos propusimos abordar aquí partiendo de una relectura de Mínima Moralia.

En tal sentido, y retomando ahora algunos de los elementos desplegados, digamos que Adorno extraña el modo en que solemos pensar los problemas de la democracia por lo menos de tres modos. En primer lugar, y a propósito del carácter situado del pensamiento y la no "eternidad" de las categorías filosóficas, "individuo" pero también "colectivo", "política", "totalitarismo" o "democracia" dejan de constituirse como los tópicos perennes de la filosofía, para tener que ser leídos en su constelación y remitidos al tipo de relaciones sociales involucradas en la definición de su concepto en cada caso. (Por ejemplo: relaciones sociales reducidas al modelo contractual, empobrecidas en términos dicotómicos, etc.).

En segundo lugar, el tema de la no originariedad de ninguna de estas categorías se asocia a lo relativo de su valor de verdad. Pero "relativo" no "en general", al modo de un relativismo que aceptaría gustoso que cada uno privilegie la que quiera y monte su edificio a partir de allí, sino en el sentido que mentábamos el carácter condicional de la relación que la categoría de individuo sostiene con la verdad de acuerdo a su posición decadente o triunfal; subordinada, central o periférica; rutilante o vetusta; celebrada o vapuleada, en coyunturas precisas. Apelando a la noción de ideología, podríamos reformular lo anterior diciendo que una interrogación de aquellos términos que mentábamos más arriba no puede darse independientemente de lo que funciona como ideología en un momento determinado. Esto es, no puede darse sin interrogar la posición que esos términos tienen, o no, en la configuración de los ideologemas centrales de una época y que pueden convertir al individuo en una ideología, pero también a la (anti)política, la tecnocracia, la nación e incluso la democracia (sobre todo si es liberal y del consenso) en ideologías. 
En tercer lugar, y como decíamos a propósito de la doble valencia de la inactualidad del individuo en Mínima Moralia, pero también del mismo presupuesto de la armonía esencial de lo social que lo rebaja de antemano, surge la necesidad de no osificar el concepto de lo ideológico en una unidad sin tensiones ni reducirlo a un sólo y mismo nivel: si en la primer entrada que planteamos ideológica es la confianza en que aún goza de buena salud lo que ya ha fenecido y se fortalece un cadáver (confianza en que es presente lo ya inactual), en la segunda se llama ideología a la pretensión de que la promesa se ha cumplido (pretensión de que ya es presente lo aún pendiente), y en el tercero se muestra la solidaridad entre esas absolutizaciones del individuo y una representación dominante de la sociedad: en el postulado (liberal) de la armonía social se elabora la aniquilación del individuo antes de que el liberalismo se pronuncie respecto a él.

Finalmente, en el entrelazamiento de estos elementos resultan legibles las distancias de Adorno, en tanto pensador singular, con las tradiciones más incisivas de la teoría política. En primer lugar, distancia con la tradición liberal en la que Adorno parecería instalarse y que es objetada tanto por Schmitt como por el marxismo: tampoco para Adorno el individuo es un terminus a quo, y es más bien la experiencia que el individuo tiene de sí mismo en la edad de su decadencia la que contribuye a formular la crítica del individuo como ideología en su época de esplendor. Sin embargo, a diferencia de Schmitt, para Adorno el individuo en el sentido de una individuación no domesticada bajo la lógica de la comparabilidad y la competencia sino modulada por las potenciales afinidades y el impulso mimético, sí es un extraño terminus a quo, punto de llegada deseable. No obstante, ese advenimiento dista de representar un simple triunfo del individuo sobre la totalidad, e implica en cambio una trasmutación de ambos que interviene críticamente sobre el par "individuo como principio"/ "sociedad armónica" sostenido por el liberalismo (aunque vigente mucho más allá de él en figuras antiliberales o no liberales que sostienen la primacía de alguna objetividad transindividual dotadora de sentido a un real carente de él). En último término, y a diferencia de ciertas tendencias postfundacionalistas de la teoría política, la figura del individuo que en planteo de Adorno es "extrañada" y no sencillamente negada, es a su vez más que un puro vacío o no-ser actual, más que una pura espectralidad amenazante. Como intentamos mostrar, en la crítica de los supuestos, principios y evidencias del individuo Adorno no se limita a la pura espectralización sino que aquél emerge, en 
cambio, como una fuerza de resistencia real $y$ limitada que "exhorta" desde su acotamiento a "poner fin a esa fatalidad que individúa a los hombres únicamente para poder separarlos tanto más perfectamente en su aislamiento". ${ }^{29}$

Correo electrónico: giselacatanzaro@yahoo.com

Dirección postal: Santiago del Estero 674, piso 6, CABA, Argentina.

${ }^{29}$ Citado más arriba (nota 14$)$. 